\title{
CIBERCULTURA
}

\section{PLATAFORMAS ALGORÍTMICAS: INTERPELAÇÃO, PERFILAMENTO E PERFORMATIVIDADE}

\author{
ALGORITHMIC PLATFORMS: INTERPELLATION, PROFILING AND \\ PERFORMATIVITY
}
PLATAFORMAS ALGORITTMICAS: INTERPELACIÓN, PERFILAMIENTO Y PERFORMATIVIDAD

Julio Cesar Lemes de Castro'

RESUMO: este trabalho de articulação teórica, ancorado em pesquisa bibliográfica, considera como plataformas algorítmicas as redes de acesso controlado nas quais o usuário é governado via algoritmos e sua identidade é redefinida continuamente com base em dados fornecidos por ele ou extraídos de sua atividade. Para entender as circunstâncias em torno da interação do usuário com essas plataformas, o artigo propõe e desenvolve categorias que adaptam e reformulam elementos conceituais de diversas origens. A interpelação refere-se à abordagem do usuário pelo algoritmo, que é recalibrada a cada iteração e cuja agência pode distribuir-se em instâncias de alteridade representadas pelo algoritmo ou por outros atores. Tal abordagem opera por meio da definição ad hoc de perfis a partir da combinação de traços do usuário, o perfilamento. Este, por sua vez, consolida-se em virtude de sua assunção pelo usuário, que corresponde à performatividade.

Palavras-Chave: Plataformas algorítmicas. Interpelação. Performatividade.

ABSTRACT: algorithmic platforms are networks with controlled access in which the user is governed by algorithms. On these platforms, the user's identity is continually 
redefined based on data provided by him or extracted from his activity. This is the case of Google services; social networks such as Facebook; e-commerce sites such as Amazon; streaming providers such as Netflix and Spotify; sharing economy services such as Uber and Airbnb; and devices connected to the internet of things, such as wearable technologies. In order to analyze the user's interaction with these platforms, this work of theoretical articulation draws on three categories. Interpellation is the algorithm approach to the user, recalibrated at each iteration. This approach operates through profiling, i.e., the ad hoc definition of profiles grounded on the combination of user traits. Profiling, in turn, is consolidated by virtue of its assumption by the user, which corresponds to performativity.

Keywords: Algorithmic platforms. Interpellation. Performativity.

RESUMEN: plataformas algorítmicas son redes de acceso controlado en que el usuario es gobernado vía algoritmos. En ellas la identidad del usuario es redefinida continuamente en base a datos proporcionados por él o extraídos de su actividad. Es el caso de los servicios de Google; de redes sociales como Facebook; de sitios de comercio electrónico como Amazon; de proveedores de transmisión continua como Netflix y Spotify; de servicios de economía del compartir como Uber y Airbnb; y de dispositivos acoplados a internet de las cosas como las tecnologías de vestir. Para analizar la interacción del usuario con tales plataformas, este trabajo de articulación teórica recurre a tres categorías. La interpelación es el abordaje del usuario por el algoritmo, recalibrado a cada iteración. Tal abordaje opera a través de la definición ad hoc de perfiles a partir de la combinación de rasgos del usuario, el perfilamiento. Este se consolida en virtud de su asunción por el usuario, que corresponde a la performatividad.

Palabras Clave: Plataformas algorítmicas. Interpelación. Performatividad.

\section{Introdução}

Em relação à noção de governamentalidade, lançada por Foucault, a de governança tem conotações mais corporativas e horizontais, que se associam naturalmente a dois fenômenos contemporâneos e entrelaçados: o neoliberalismo e o uso de algoritmos. O presente artigo enfoca a governança algorítmica que viceja na sociedade neoliberal, com destaque para a posição do usuário no que chamo de plataformas algorítmicas. A intenção é iluminar as circunstâncias que presidem a interação do usuário com tais plataformas, incluindo tanto a forma como ele é abordado quanto sua participação voluntária e ativa. 
Plataformas algorítmicas são consideradas aqui aquelas em que o usuário é governado via algoritmos. Se as instituições disciplinares eram os braços da sociedade disciplinar, as plataformas algorítmicas materializam a governança algorítmica.

A rigor, qualquer sítio da world wide web, na medida em que recolha dados dos visitantes e os utilize para direcionar sua navegação, pode funcionar como uma plataforma algorítmica. Entretanto, esse rótulo é aplicável, sobretudo, àqueles que funcionam como espaços privados e exigem cadastro dos usuários para acesso a seus recursos, representando, de acordo com o inventor da web, Tim Berners-Lee (2010), "um silo fechado de conteúdo". É o caso dos serviços do Google, tomados conjuntamente, de redes sociais como o Facebook e de sites de comércio eletrônico como a Amazon. Contam-se entre essas plataformas, ademais, provedores de transmissão contínua ou fluxo de mídia (streaming), como a Netflix e o Spotify, serviços de economia do compartilhamento, como o Uber e o Airbnb, e dispositivos acoplados à internet das coisas, como as tecnologias vestíveis.

O artigo não visa esmiuçar a engrenagem de cada modalidade de plataforma, mas proceder a um exame mais abrangente de como os usuários são afetados nelas. Trata-se, pois, de um esforço eminentemente teórico de articulação para desvelar as características da trama algorítmica em redor do usuário, estabelecida de maneira similar nas diferentes plataformas.

A interpelação, que consiste na abordagem do usuário pelo algoritmo, é uma operação recursiva, recalibrando-se incessantemente sob o influxo das reações ocasionadas e do input recebido. A agência da interpelação pode distribuir-se em várias instâncias de alteridade, representadas pelo próprio algoritmo ou por outros atores. O perfilamento equivale à definição de perfis, através da interpelação, pela combinação ad hoc de traços do usuário. E a performatividade corresponde ao efeito da interpelação, no sentido de consolidação do perfilamento.

\section{Interpelação recursiva}

A governança algorítmica prima pela recursividade: os dados fornecidos por alguém, ou dele extraídos de algum jeito, determinam aquilo que lhe será exibido ou recomendado de forma customizada. Em outras palavras, as informações geradas no interior de um sistema se prestam a retroalimentá-lo. Isso se dá nomeadamente no espaço restrito de uma plataforma, cada qual funcionando de modo relativamente estanque (é verdade que órgãos governamentais de inteligência, como a National Security Agency norte-americana, têm acesso a dados de plataformas distintas e podem cruzá-los, mas tal cruzamento em princípio não reverte diretamente para o usuário, a não ser quando ele é interpelado como suspeito). 
A recursividade orienta o comportamento dos usuários nas plataformas algorítmicas. A cada um são oferecidos certos estímulos, selecionados e hierarquizados consoante o potencial que teriam de instigar sua ação. Ou seja, em tais plataformas há uma espécie de interpelação recursiva dos usuários.

Falar em interpelação remete-nos obviamente a Althusser. Para ele, o indivíduo é constituído como sujeito, pela ideologia, ao reconhecer-se como alvo de uma interpelação que lhe chega do exterior, sujeitando-se à determinação desta. $O$ exemplo clássico é o do transeunte que, ao ouvir de um policial um chamado do tipo "Ei, você aí!", se volta em direção ao autor do enunciado, assumindo-se como o destinatário da interpelação (ALTHUSSER, 1995, p.305). O arrimo da etimologia providencia uma chave imediata para clarificar essa operação. "Interpelação" deriva do latim "interpellatio", que denota tanto interrupção como intimação. As duas acepções transparecem na cena entre o transeunte e o policial, na qual o primeiro detém-se ao saber-se visado pelo segundo.

Neste trabalho, o fecundo e controverso conceito de Althusser serve tão-somente como ponto de partida para caracterizar a interpelação algorítmica. Guarda-se aqui uma distância teórica quanto às formulações althusserianas, particularmente, como será mostrado mais tarde, no que tange ao uso da psicanálise. Além do mais, a interpelação algorítmica tem discrepâncias fundamentais vis-à-vis à interpelação em Althusser, que dizem respeito a seu agente, a seu teor e à maneira como ela se dá, tornando-se necessária uma série de adaptações.

$\mathrm{Na}$ abordagem do transeunte pelo policial, temos um vínculo comunicativo alicerçado numa posição de autoridade. Esse vínculo e essa posição aparecem também sob a forma da dupla dimensão da cibernética, como comunicação e controle, consignada no título da obra de Wiener (1961), publicada originalmente em 1948, e que populariza o termo "cibernética".

No singelo programa que ilustra ordinariamente a sintaxe de uma linguagem de programação, provendo como saída a saudação “Hello, world!", já se evidencia a dimensão de comunicação. Esta, por seu turno, desdobra-se naturalmente na dimensão de controle. Kittler (2014, p.149) traça, a propósito, um paralelo entre os "comandos" de software, designação que ele reputa bastante significativa e mais apropriada do que "instruções", e a interpelação althusseriana. A equação de Kowalski (1979) traz uma versão ligeiramente modificada das duas dimensões: "algoritmo = lógica + controle".

Mas como se situa alguém relativamente à interpelação algorítmica? Para Manovich (2001, p. 61), as operações interativas no ambiente digital consistem numa externalização de nossas operações mentais. Se outrora uma imagem despertava em nós uma associação mental com outra, agora essa associação 
está pré-programada no sistema, na forma de um link que nos é disponibilizado para clicar. Deparamo-nos então, segundo Manovich, com uma atualização da interpelação althusseriana, tendo em vista que somos induzidos a tomar a estrutura mental de outra pessoa (responsável pela programação) como a nossa. Contudo, quando se trata de um link ou de quaisquer outras opções que alcançam o usuário por intermédio de um algoritmo, esse processo torna-se mais complexo.

Nas plataformas algorítmicas, pode-se afirmar que somos compelidos a tomar como nossa uma simulação de nossa própria estrutura mental, mas feita por outrem e otimizada conforme seus interesses. O conteúdo da abordagem via algoritmos não é alheio ao receptor, mas escora-se em traços oriundos dele, reverberando de algum modo suas reações e seu input. A interpelação parte de alguém e regressa a ele modificada. Esse questionamento recursivo é i(n)terativo, ostentando um componente interativo, a participação atuante do usuário, e um componente iterativo, que leva em conta aquela participação para apurar a interpelação a cada iteração.

Em matéria de controle, a interpelação algorítmica equivale a "uma modulação, como um molde autodeformante que muda continuamente, de um momento para outro" (DELEUZE, 2003, p. 242, grifo do autor). Note-se que Simondon (2010), cuja noção de modulação inspira a de Deleuze, emprega essa noção num texto de 1962 ao analisar o modo de operação dos amplificadores, objetos técnicos que estão na origem do termo "feedback", que indica recursividade. Na prática, a interpelação algorítmica usa a iniciativa do próprio usuário para controlá-lo, tal como em certas técnicas orientais de artes marciais o lutador se aproveita da força do oponente para derrubá-lo.

O filósofo esloveno Mladen Dolar (2006, p. 3-4) narra uma pequena anedota como amostra de uma interpelação falhada. Um grupo de soldados italianos está entrincheirado e, no calor da batalha, seu comandante conclama: "Soldados, ataquem!" Apesar disso, ninguém se mexe. Irritado, ele volve a ordenar num tom mais alto, e novamente nada acontece. Quando o comandante grita pela terceira vez, ouve-se um comentário nas trincheiras: “Que bela voz!”. Fazendo jus ao estereótipo, arremata Dolar, os italianos não atendem à convocação como soldados, mas como aficionados da ópera.

Ora, se um episódio análogo ocorresse no interior de uma plataforma algorítmica, digamos uma rede social como o Facebook, podemos conjecturar que os desdobramentos seriam certamente distintos. Tão logo os algoritmos captassem que os usuários se mantêm impassíveis como militares, mas reagiriam como melômanos, a interpelação seria reconfigurada. A falha numa interpelação não importa em desper- 
dício, mas é reaproveitada para tornar a interpelação subsequente mais eficaz. Esse ciclo constante de correção e redirecionamento enquadra-se na função recursiva.

Um paralelismo com a discussão foucaultiana sobre o cuidado de si nos antigos pode ser-nos proveitoso. Em seu curso de 1981-1982 no Collège de France, A hermenêutica do sujeito, Foucault (2001, p. 237-238) elenca uma gama de expressões em grego e latim nas quais aparece, de um lado, o deslocamento de alguém em relação a si e, de outro, o retorno a si. A metáfora por excelência que elucida essas operações, arrazoa Foucault (2001, p. 238-239), é a da navegação, que engloba as ideias de movimento, de destino, de retorno à origem, de risco e de pilotagem.

$\mathrm{Na}$ interpelação recursiva que se verifica nas plataformas algorítmicas, podemos identificar a ideia de movimento na atividade do usuário, a partir da qual são obtidos dados sobre ele, e as ideias de destino e de retorno à origem na interpelação propriamente dita, customizada para cada usuário com base naqueles dados. Também a ideia de risco está arraigada na governança algorítmica, visto que, ao prever comportamentos, busca transformar a incerteza em risco a ser gerenciado. Finalmente, a ideia de pilotagem, кußźpvnoıৎ (kubérnēsis) em grego, é recuperada no próprio étimo de "cibernética".

Assomando já no hipertexto (NIELSEN, 1990), a metáfora da navegação é utilizada desde o início na web, à qual ela se amolda perfeitamente (HOCHMAIR; LUTTICH, 2006). Na língua portuguesa isso é ainda mais patente, posto que chamamos os browsers, programas para acessar a web, de "navegadores". Um dos primeiros navegadores comerciais, que domina o mercado em meados dos anos 1990, é o Netscape Navigator, cujo símbolo é um timão. E é, justamente, como um recurso dele que despontam os cookies, os quais, colhendo informações dos internautas, permitem que sejam interpelados algoritmicamente mediante anúncios personalizados, pavimentando o trajeto para as plataformas algorítmicas atuais na web.

A interpelação algorítmica é recursiva não apenas por respaldar-se em dados do usuário, mas também por responder a uma demanda dele. Num mecanismo de busca como o Google, digitamos ou falamos algo para pôr em marcha uma pesquisa; numa rede social como o Facebook, acedemos a nosso feed de notícias com a expectativa do que vai cativar nossa atenção; numa loja on-line como a Amazon, buscamos algum produto ou consultamos as sugestões. Todas essas situações equivalem a uma espécie de demanda de nossa parte, porquanto nos disponibilizamos mais ou menos ativamente a receber uma interpelação externa. Há uma adaptação recíproca nos casos de demanda à plataforma pelo usuário e interpelação deste pela plataforma.

O usuário aprende a acatar as regras da plataforma, por exemplo, ao digitar palavras-chave relevantes quando faz uma consulta em mecanismos de busca 
ou usar uma entonação clara e pausada ao proferir uma questão diante de um software de reconhecimento de voz. Por outro lado, agentes inteligentes, como o Siri, da Apple, aprendem através da interação com os usuários.

Num texto acerca dos laços sociais na cibercultura (Autor, ref.1), associei a demanda que brota do usuário ao discurso da histeria, tal como esquematizado por Lacan, no qual o sujeito aparece na postura de questionamento em face de um senhor ou mestre, advindo dessa relação à produção de um saber. Nessa perspectiva, as plataformas algorítmicas acarretam uma sorte de histericização dos usuários (não do ponto de vista patológico, mas de uma estrutura peculiar de laço social), ao condicioná-los a esperar por respostas ou recomendações.

Em termos lacanianos, poderíamos dizer que a demanda corresponde a uma tentativa de tamponar provisoriamente a falta intrínseca à condição subjetiva. É como se o retângulo em branco no centro de gravidade da página inicial deliberadamente despretensiosa do Google simbolizasse essa lacuna.

No limite, chega-se à "conclusão lógica de nosso relacionamento com os computadores: digitar com expectativa 'qual é o sentido de minha vida?' no Google", graceja o filósofo Alain de Botton (citado por GLEICK, 2011). E, se o usuário se coloca na posição de questionamento típica do sujeito histérico, o mecanismo de busca aparece como a encarnação do senhor que tem as respostas. Alan Cohen, vice-presidente de uma empresa provedora de wi-fi, aventura: "O Google, combinado com o wi-fi, é um pouco como Deus. Deus é sem fio, Deus está em todo lugar e Deus vê e sabe tudo" (COHEN, citado por FRIEDMAN, 2003). O próprio Google aspira a colocar-se nessa posição, como transparece numa declaração de seu cofundador Sergey Brin ao editor-chefe da MIT Technology Review: "O mecanismo de busca perfeito seria como a mente de Deus" (FERGUSON, 2005). Chega-se a cogitar, inclusive, uma religião paródica ancorada nessa nova divindade: "Nós, da Igreja do Google, acreditamos que o mecanismo de busca Google é o mais próximo que a humanidade já chegou de experimentar diretamente um Deus de fato" (MACPHERSON, 2008, grifo do autor).

É verdade que o questionamento por parte dos usuários tende a ser sutil, pois as plataformas procuram antecipar-se a suas demandas, adivinhar o que eles querem. A própria evolução técnica das plataformas percorre esse itinerário. Aglutinando diversos serviços (mecanismo de busca, Gmail, YouTube, Maps, Drive etc.) sob um único guarda-chuva, o Google lança mão de dados coletados do usuário em um deles para refinar suas respostas e recomendações em outro.

No começo do Facebook, os usuários tinham de ir até a linha do tempo de seus amigos para ver suas postagens; com a introdução do feed de notícias, em 2006, as postagens dos amigos passam a ser expostas automaticamente para cada um; e, 
com a proliferação de conteúdos no decurso do tempo, a triagem do que compõe o feed de notícias torna-se mais rigorosa e o encargo dos algoritmos nessa tarefa é ampliado. $E$, uma vez que o usuário tem consciência de que o que será oferecido a ele está atrelado a seu input e sua atividade, ao tentar corrigir e aprimorar o que Ihe é apresentado (por exemplo, reagindo a sugestões de livros da Amazon com esclarecimentos adicionais sobre os que ele já tem ou não lhe interessam) ele está na prática dirigindo-se ao algoritmo em pós de melhores indicações.

A recursividade da interpelação não se dá exclusivamente no campo individual, mas envolve o coletivo. É verdade que o que nos interessou antes é erigido em parâmetro pelos algoritmos para presumir o que nos interessaria agora. Mas, para fazer a ligação entre o que nos atraiu e o que possivelmente nos irá atrair é mister inspirar-se em instâncias em que essa ligação já aconteceu, as quais mostram como o percurso entre uma coisa e outra foi trilhado por outros usuários. Com o recurso de preenchimento automático no Google, que leva em conta as questões mais frequentes feitas por outros, antes mesmo de completar sua questão o usuário recebe sugestões sobre o que perguntar.

Quando consultamos ou adquirimos um livro na Amazon, somos cientificados da afinidade dessa obra com tais e tais outras obras, deduzida dos dados coletados de outros clientes. A interpelação carrega em si informações de nossas ações passadas, mas cotejadas com padrões emanados de ações passadas de todos os outros. $\mathrm{Na}$ medida em que os padrões são definidos com base no coletivo, poucas informações sobre nós já são suficientes para as inferências desejadas, o que torna irrelevantes, aliás, muitas iniciativas dirigidas à proteção de dados (OTTERLO, 2014, p. 262).

Trocando em miúdos, o algoritmo identifica-nos com outros, como nossos semelhantes, e agrega essa identificação à interpelação que nos é dirigida. Ao lidar com isso, assumimos a identificação com nossos semelhantes, que no linguajar lacaniano consiste numa relação imaginária.

\section{Agentes da interpelação}

A par do outro imaginário, o semelhante com o qual somos identificados e terminamos por nos identificarmos, a interpelação algorítmica concerne o Outro simbólico, a autoridade responsável pela interpelação (minúscula e maiúscula, na convenção adotada por Lacan, representam respectivamente o imaginário e o simbólico, que, junto com o real, perfazem os três registros da experiência humana).

Como nos adverte Butler (1997, p. 106), a cena entre o transeunte e o policial narrada por Althusser deve ser interpretada alegoricamente, pois não é um proces- 
so diádico, e o chamado pode vir de maneira implícita, não-dita. Isso é ressaltado na governança algorítmica, na qual a autoridade não figura tão explicitamente.

Reportando-se à interpelação mediante bancos de dados, Poster (1995, p. 90) pondera que ela se diferencia de situações presenciais típicas (entre policial e transeunte, chefe e funcionário, professor e aluno, pai e filho), aproximando-se da interpelação in absentia entre escritor e leitor, e só divergindo da última porque costumamos escolher de forma deliberada o que lemos, enquanto o que nos chega por meio de bancos de dados é de índole mais fluida.

Na verdade, o agente da interpelação algorítmica é relativamente indeterminado, visto que o funcionamento dos algoritmos é nebuloso - o código aparece aqui na acepção de algo que precisa ser decifrado. Pode-se dizer que os algoritmos constituem uma caixa preta, e que, em função de sua disseminação, vivemos hoje numa autêntica "sociedade caixa-preta" (PASQUALE, 2015).

Historicamente, o usuário das plataformas algorítmicas conflui com o sujeito neoliberal contemporâneo (Autor, ref. 4). Este é qualificado por Foucault (2004, p.232), em seu curso de 1978-1979, O nascimento da biopolítica, como "empreendedor de si mesmo". Nele, o cuidado de si envolve certas "técnicas de si". Analisando essas técnicas em outro contexto, da antiguidade, Foucault (1994b) realça a importância da "escrita de si", que abarca relatos e reflexões ensejados pela vivência diária. Escreve-se no formato de correspondência, que engaja manifestamente outra personagem, ou de caderneta de anotações (hupomnêmata), que é feita para si, mas funciona como um companheiro. O Outro presente na escrita equivale, portanto, a uma espécie de mentor virtual.

Lembrando que Foucault (1994a, p. 403), numa entrevista, equipara o impacto do hupomnêmata sobre a vida cotidiana na época de Platão ao do computador hoje, poderíamos fazer um paralelo entre a posição de onde parte a interpelação algorítmica e a posição do Outro na escrita de si. Mas, o agente da interpelação algorítmica tem, outrossim, algo em comum com outra modalidade de guia, o expert moderno (médico, terapeuta, assistente social etc.), coletando e sistematizando, numa escala ainda maior do que esse, informações atinentes a cada um.

$\mathrm{Na}$ realidade, cumpre discernir duas classes de agência nas quais se ramifica a interpelação algorítmica. Por um lado, o algoritmo propriamente dito, ao organizar e nortear a interpelação embute em si um agente impessoal, uma autoridade incrustada no aparato. Uma combinação de funcionalidades e restrições nas plataformas, como no caso do Facebook (MORRISON, 2014), formata rigorosamente tanto a interpelação quanto a resposta do usuário a esta. 
Detrás do algoritmo, há o poder dos programadores e dos proprietários das plataformas (sabe-se que Mark Zuckerberg, fundador e principal acionista do Facebook, chega a interferir pessoalmente no algoritmo que gere o feed de notícias do site). Quando o usuário é questionado pelo formulário de status do Facebook ("No que você está pensando?") ou do Twitter ("O que está acontecendo?"), é esse agente impessoal que a ele se dirige. Quando ele se depara com os conteúdos selecionados e hierarquizados pelas redes sociais, é esse agente impessoal que subjaz à filtragem.

Por outro lado, a agência da interpelação pode também se distribuir subsidiariamente por diversos atores. No âmbito das redes sociais, executam precipuamente esse papel de criadores de conteúdo (jornalistas, publicitários, youtubers), personalidades notórias de várias áreas, usuários que granjeiam prestígio por conta de sua intensa participação, ou robôs.

Nesse universo aparentemente caótico ordenado pelo algoritmo, a sua predominância, potencializado pela recursividade, e a multiplicidade dos formadores de opinião relativizam o status de instâncias tradicionais de mediação, como o jornalismo. No limite, cada um de nossos contatos (ou até contatos de contatos, através dos últimos) nos interpela, na medida em que somos instados pela plataforma a reagir de alguma forma a sua ação.

Para Foucault (2001, p. 123), não apenas a escrita de si, mas o cuidado de si em geral, tal como se apresenta na antiguidade, carece de uma figura de alteridade. "Outrem, o outro, é indispensável na prática de si, para que a forma que define essa prática atinja efetivamente seu objeto, isto é, o eu, e seja por ele efetivamente preenchida". Essa figura de alteridade encaixa-se num dos três tipos de mestria (FOUCAULT, 2001, p. 123-124). O primeiro é a mestria como exemplo, daquele que faz as vezes de modelo de comportamento, como é o caso dos heróis e dos mais velhos. $O$ segundo é a mestria pela competência, daquele que é capaz de transferir conhecimentos, diretrizes morais, aptidões e assim por diante. $\mathrm{O}$ terceiro é a mestria via maiêutica, à feição socrática.

Poderíamos relacionar as classes de agência da interpelação algorítmica a esses três tipos de mestria. Os formadores de opinião no interior das plataformas, encarnados concretamente em pessoas, grupos ou empresas, corresponderiam à mestria como exemplo e à mestria pela competência. Já o agente impessoal embutido nos algoritmos corresponderia à mestria via maiêutica. Lembremos que, para Sócrates, o desafio da educação é duplo: saber que não se sabe e, ao mesmo tempo, saber que se sabe mais do que sabe. Este último saber é descortinado pela maiêutica, método de prodigalizar perguntas de modo a fazer com que alguém descubra por si só alguma coisa. 
Ora, nas plataformas algorítmicas, que também trabalham com um estratagema de aproximações sucessivas, é como se o usuário fosse concitado a saber que não sabe, e por isso amparar-se na plataforma, e concomitantemente a saber que sabe mais do que pensa que sabe, visto que os algoritmos Ihe trazem (indiretamente, por meio da recursividade da interpelação) informações sobre si das quais ele próprio nem sempre tem consciência.

Uma outra referência para apreender a agência da interpelação algorítmica é proporcionada pela psicologia de massa freudiana (CASTRO, ref. 2). Para Freud (1967a), a massa é constituída pela identificação entre si de cidadãos que compartilham um elo libidinal com o mesmo líder. Ele pode ser principal ou secundário, e pode ter um cunho abstrato (como uma ideia) ou concreto (como uma pessoa).

Numa dada plataforma algorítmica, o conjunto de usuários perfaz uma massa unificada abstratamente por uma ideia (o algoritmo), que exerce a incumbência de líder principal. Dentro dessa totalidade proliferam recortes específicos (um usuário pertencendo simultaneamente a vários recortes), cada um deles compondo uma massa particular, congregada em volta de um líder secundário, que pode ser concreto (uma determinada pessoa) ou abstrato (uma determinada visão de mundo ou preferência).

\section{Perfilamento bidirecional}

Na fórmula de Althusser (1995, p. 302), "a ideologia interpela os indivíduos como sujeitos". Posto de outra maneira, sua tarefa é "'constituir' indivíduos concretos como sujeitos" (1995, p.303). Ou seja, para ele a interpelação equivale a uma subjetivação. Entretanto, sopesando essa operação à luz de conceitos psicanalíticos, em especial lacanianos (sem nos subordinarmos à apropriação deles pelo próprio Althusser), e atentando para as especificidades da interpelação algorítmica, seria mais adequado descrevê-la num sentido distinto do aventado por ele. Em vez de subjetivação, este artigo propõe qualificá-la como perfilamento.

Convém lembrar que o ensino de Lacan na década de 1950 é marcado pela forte influência da teoria dos jogos e da cibernética. Juntamente com a linguística e a antropologia estruturais, essas referências contribuem para o desenvolvimento de sua concepção de simbólico, que está no cerne do funcionamento do inconsciente. Discorrendo nessa época sobre estratégias passíveis de ser empregadas no jogo de par ou ímpar, Lacan argumenta que nosso inconsciente tende a seguir padrões, ainda que não adotemos um arranjo premeditado.

Como Freud (1941) demonstra em Psicopatologia da vida cotidiana, se alguém nos pedir para dizer qualquer número dentro de certo intervalo, não nos inclina- 
mos por um número de modo inteiramente aleatório, mas à força de associações mentais. A existência de uma lógica no inconsciente relaciona-se com a possibilidade de previsão. Freud (1961, p. 626) sustenta que a crença ancestral no caráter profético dos sonhos tem algum fundamento, pois, "ao imaginar um desejo como realizado, o sonho nos leva ao futuro; mas esse futuro, tomado pelo sonhador como presente, é moldado pelo desejo indestrutível à imagem e semelhança do passado".

Levantando conjecturas sobre um computador que um dia fosse capaz de detectar padrões inconscientes, Lacan (1966, p. 59) sublinha o extraordinário potencial de antevisão que essa capacidade lhe concederia: "Não é impensável que uma moderna máquina de calcular, isolando a frase que, sem que ele o saiba e a longo prazo, modula as escolhas de um sujeito, venha a ganhar além de qualquer proporção costumeira no jogo de par ou ímpar". Essa especulação articula-se com uma advertência no tocante aos riscos do poder amealhado pelo computador, quando ele menciona "a mais moderna das máquinas, muito mais perigosa para o homem do que a bomba atômica, a máquina de calcular" (LACAN, 1978, p. 111).

Na interpelação do transeunte pelo policial, não é difícil divisar as vertentes constitutivas do simbólico lacaniano, a linguagem e a lei. Isso sucede também na interpelação algorítmica. É interessante notar que a palavra "código", usada em programação, alude diretamente à linguagem bem como à lei. "Código é lei", intitula-se o primeiro capítulo do livro de Lawrence Lessig (2006).

Além disso, os algoritmos pressupõem uma lógica no comportamento do usuário e fazem inferências acerca de seu comportamento vindouro esteadas em seus desejos expressos previamente. Os traços deixados pelas atividades e interações dos usuários, máxime quando elas são mais intensas e se protraem por bastante tempo, seguem padrões que representam aspectos dos quais os próprios usuários nem sempre se dão conta.

Na medida em que os padrões reconstituídos a partir dos traços escapam a alguém, eles têm um paralelismo com os sintomas, sonhos, chistes e lapsos - as formações do inconsciente, através das quais se exprime. As plataformas algorítmicas, que processam um grande volume de dados por um longo período e confrontam dados de diferentes usuários, estão habilitadas a captar padrões de comportamento com uma exatidão por vezes surpreendente.

Para Lacan (1975, p. 95), "a situação do sujeito [...] é caracterizada essencialmente por seu lugar no mundo simbólico". Pensado sob a perspectiva de sua sujeição à ordem simbólica, ou seja, de seu enquadramento por intermédio da linguagem e da lei, o sujeito tem uma dimensão social. Ele aparece também como 
sujeito do inconsciente, manifestando-se mediante irrupções dele e, tendo assim, uma dimensão interior igualmente sob a égide da linguagem e da lei.

Entre as duas dimensões há uma continuidade, capturada pelo neologismo lacaniano "extimidade", fusão de "exterior" e "intimidade", e pela figura topológica da banda de Möbius, cara a Lacan. A interpelação algorítmica incide sobre o sujeito nessas duas dimensões, seja por envolver uma dimensão social cristalizada na linguagem e a lei, seja por valer-se de traços que têm um paralelismo com manifestações do inconsciente.

Discutindo as inconsistências da fórmula althusseriana da interpelação, Žižek (1993, p. 74) salienta que, "na ideologia liberal clássica, o sujeito é interpelado precisamente como 'indivíduo'", ou seja, justamente o oposto do que preconiza Althusser. Nessa trilha, autores como Silveira (1994) e Dean (2016) sugerem simplesmente inverter a fórmula geral: a ideologia interpela o sujeito como indivíduo, não o contrário. Essa inversão encara o repto de retificar a interpelação de Althusser, recolocando-a sobre seus próprios pés, como advoga Marx (1962, p. 27) em relação à dialética hegeliana.

A fórmula invertida é válida para a modernidade em geral - aplica-se às instituições disciplinares, por exemplo, que individualizam aqueles a elas submetidos. E retrata o modus operandi da ideologia sob o capitalismo, que eclipsa a dimensão social do sujeito ao promover o individualismo burguês. Como o indivíduo corresponde ao eu, situando-se no registro do imaginário, a ideologia é então uma refração provocada pelo imaginário.

Estender esse raciocínio para a interpelação algorítmica, porém, impõe cautela. A inversão deve ser complementada com um passo adicional: o sujeito não é interpelado precisamente como indivíduo, mas como perfil. Partindo dos traços abstraídos do usuário, e identificando padrões que articulam esses traços, as plataformas algorítmicas constroem montagens, ou perfis, reproduzindo tais padrões.

Como afirma Flusser (2008, p. 123), a propósito do que ele chama de "revolução telemática", as quantidades nas quais as qualidades se desintegram se reintegram em algo semelhante a qualidades. O perfil é uma montagem parcial, ad hoc, agrupando traços selecionados.

Portanto, o usuário é apreendido pelos algoritmos como uma coleção de perfis, que espelham suas preferências. A cada um, por sua vez, corresponde a um modelo. O perfil é uma suposição sobre o que interessa ao usuário; já o modelo é a opção colocada à disposição do usuário para satisfazer, por meio de identificação, aquele interesse.

Tal como concebido pelos algoritmos, o perfil não é visível, mas pode ser deduzido do modelo correspondente, que procura dar conta dele. Cada interpelação, por conseguinte, encerra uma díade perfil-modelo. Ela traduz-se na operação 
de perfilamento, isto é, na definição de um perfil, que se desdobra na oferta de um modelo que lhe acompanha. Nas plataformas algorítmicas, não há interesse em desbordar a visão fragmentada dos usuários fornecida pelo perfilamento. $O$ usuário só é interpelado sob ângulos específicos, por exemplo, como consumidor latente de certo produto ou serviço.

Como na frase de Kittler (1986, p. 5), "o que fica das pessoas é sempre apenas aquilo que a mídia pode armazenar e transmitir"; no caso, o que subsiste no perfil considerado a cada momento é uma espécie de sinédoque do usuário. $\mathrm{E}$, do prisma coletivo, a interpelação não se dirige a uma massa de usuários tomados como indivíduos, mas a um aglomerado (cluster, no jargão das redes) de perfis tomados a um recorte de usuários, que constitui um nicho.

Isso não significa que não se possa mais pensar em termos de indivíduos; o que ocorre é que a individualidade se torna muito mais fluida e instável. No neoliberalismo, a ideologia capta o sujeito de maneira segmentada. Na qualidade de empreendedor de si, o sujeito neoliberal tem seus atributos isolados e quantificados como capital humano. A interpelação algorítmica obedece à mesma lógica. A refração imaginária efetuada pela ideologia, nesse caso, consiste em focar não exatamente no eu, mas nas identificações com os modelos, correlativos aos perfis.

Essas identificações são os ingredientes que compõem o eu, sumariado por Freud (1967b, p. 257) como "um precipitado das catexias objetais abandonadas, que contém a história dessas escolhas de objeto". A inversão da fórmula althusseriana tampouco elimina o sujeito: ele é invocado a cada interpelação, a despeito de esta atuar reduzindo-o a um perfil. E emerge também quando a interpelação claudica, quando o sujeito resiste à redução proposta.

Na proporção em que o usuário se identifica com um modelo, reagindo favoravelmente àquilo que the é exibido, ele aceita o perfil conexo que lhe foi designado pelo algoritmo. $O$ perfilamento culmina então em um perfilhamento. Perfilhar indica o ato de abraçar uma ideia ou teoria; no caso, trata-se do ato, por parte do usuário, de sancionar o perfil sugerido pelo algoritmo, anuindo às condições em que se é interpelado.

Em contrapartida, se deixa de seguir o modelo, o usuário rejeita o perfil, sinalizando a necessidade de refinar o algoritmo. Nessa altura, cabe ajuizar por que alguém assente à interpelação. Se para Althusser o transeunte dá meia-volta ao ser interpelado pelo policial por sentir-se culpado, Butler (1997, p. 108) alega que alguém atende ao chamado da lei acima de tudo porque este acena com a promessa de conferir-lhe identidade. $\mathrm{Na}$ interpelação algorítmica, a promessa de identidade insinua-se em cada modelo oferecido ao usuário, cada perfil delineado com base neste. 
A postura do usuário, no entanto, não é apenas reativa. Ele engaja-se pessoalmente no perfilamento de si. Isso reflete sua preocupação com a imagem, com o modo como a plataforma o apresenta e como os demais participantes o enxergam. Ademais, o usuário aposta num trade-off: graças às informações que supre voluntariamente e à tolerância com a extração de outros dados de sua participação (em matéria de contatos, atividades, preferências), ele espera um aprimoramento de seu perfilamento que reverta em seu benefício, à guisa de serviços mais eficientes e recomendações mais úteis da plataforma.

O perfilamento é destarte bidirecional, abrangendo o input do usuário e a análise do algoritmo. A interatividade, na forma da participação reativa ou ativa do usuário, implica uma certa agência por parte dele que contribui para a eficácia da interpelação recursiva.

\section{Performatividade algorítmica}

Em decorrência da interpelação, nas plataformas algorítmicas multiplicam-se os perfis de cada um, definidos ao sabor das circunstâncias. Para consolidar-se, o perfilamento requer um efeito performativo, no sentido de sua assunção pelo usuário, via conduta reativa e/ou ativa. O perfilamento origina-se, pois, da conjunção entre interpelação e performatividade.

Um enunciado performativo, em Austin (1962), é aquele que excede a mera constatação, produzindo uma sequela no momento em que é proferido. Assim, ao declarar dois nubentes como casados, cumprindo o rito apropriado, um juiz oficializa sua relação. Logo, bastaria hipoteticamente uma ocorrência solitária para engendrar o desenlace almejado pelo enunciado performativo. Indo além de Austin, todavia, pode-se atribuir a força desse enunciado a uma norma que se consagrou como tal pela aplicação reiterada; a cada cenário distinto em que o enunciado comparece, a norma é robustecida. Por isso, Derrida vislumbra nele o atributo da iterabilidade:

Poderia um enunciado performativo ter sucesso se sua formulação não repetisse um enunciado "codificado" ou iterável, ou, em outras palavras, se a fórmula que eu pronuncio para abrir uma reunião, batizar um navio ou celebrar um casamento não fosse identificável como conforme a um modelo iterável, se não fosse identificável então de alguma forma como uma "citação"? (DERRIDA, 1988, p. 18). 
Desenvolvendo esse argumento, Butler (1993, p. 12) enfatiza que o efeito performativo se assenta na repetição: "A performatividade não é, portanto, um 'ato' singular, pois é sempre uma reiteração de uma norma ou conjunto de normas". É um resultado cumulativo, derivando da citação da norma por atos reprisados, não por um ato único. E, sendo tributário da repetição - ou da "citacionalidade", como prefere o autor -, ele pode ser relacionado a outros enunciados, afora aqueles flagrantemente performativos.

Importa a Butler, em particular, a performatividade de padrões de gênero. Assim, a feminilidade é construída culturalmente na medida em que desde cedo são esperados da menina comportamentos que a sociedade vincula ao feminino, ou seja, na medida em que ela é interpelada constantemente como mulher. Se, na máxima de Simone de Beauvoir (1949, p. 13), "não se nasce mulher, torna-se mulher", isso redunda de uma pluralidade de atos, não de um ato isolado. A própria força performativa associada tradicionalmente aos agentes da interpelação decorre retrospectivamente da reiteração de sua ação, num fenômeno que Appadurai (2016), estribando-se em Butler e em estudos sobre o mercado financeiro de derivativos, qualifica como "retroperformatividade".

Para Hayles (2005, p. 50), o código de programação é performativo num grau mais pronunciado que os enunciados verbais. Estes impactam o comportamento, mas através de mediações; sua ação imediata é na mente. Em comparação, o código produz alterações efetivas na máquina em que é rodado, e eventualmente também em outras máquinas e equipamentos conectados àquela. "O código é uma linguagem", pondera Galloway (2004, p. 165, grifo do autor), "mas um tipo muito especial de linguagem. O código é a única linguagem que é executável." Nas plataformas algorítmicas, porém, o que está em causa é o efeito performativo do código no usuário, quando este é de certa forma incorporado ao circuito de manobra do código - nelas soa ainda mais pertinente a observação de Derrida (1967, p.19), para quem a cibernética, ao apropinquar homem e máquina, substitui conceitos metafísicos como o de alma pelo de programa.

Algumas escolhas na elaboração de perfis, nas plataformas algorítmicas, podem ter desenlace análogo ao de um enunciado performativo. Isso é notável, mormente naquelas que admitem o anonimato, facilitando o descolamento entre atributos on-line e off-line, logo maior latitude na definição de perfis.

Num jogo virtual no qual o usuário é interpretado por um avatar, por exemplo, ele pode avocar-se um gênero destoante de seu fenótipo. Essa opção vai caracterizá-lo doravante naquele ambiente, circunscrevendo os papéis que a plataforma lhe faculta, 
seu comportamento e a atitude de outros usuários a seu respeito. Nesse quadro, a decisão inicial tem um peso apreciável, suscitando padrões de conduta que a corroboram.

A performatividade, de qualquer forma, tende a confundir-se com a rotina de funcionamento das plataformas algorítmicas. Não se trata de um ato único, mas do saldo acumulado dos atos de interpelação ao qual ele é submetido.

O aspecto iterativo da interpelação é tonificado por sua recursividade: quanto mais eficiente ela se revela, mais é reproduzida. $E$, independentemente dos ajustes a cada nova interpelação, há elementos que se repetem. Daí provém o efeito performativo da interpelação, que consolida as operações de perfilamento: quanto mais se reproduz, maior é sua eficácia na construção de perfis. As plataformas algorítmicas não são, pois, meros veículos para a expressão de uma identidade preexistente do usuário; essa identidade é construída na própria plataforma, via interpelação, perfilamento e performatividade.

Até os anos 1990, predomina nos ambientes virtuais o anonimato, que leva ao esgarçamento da relação entre identidade on-line e off-line. Numa charge famosa de Peter Steiner, publicada em 1993 na revista New Yorker, um cachorro aparece sentado, acessando o computador, enquanto confabula com outro: "Na internet, ninguém sabe que você é um cachorro". Esse contexto favorece a multiplicação de identidades fictícias.

Entrevistado por Turkle (1997, p. 13), um estudante que usa vários perfis anônimos simultaneamente em suas interações virtuais refere-se à "vida real" (que intervém sob a forma de mensagens de pessoas que ele conhecia off-line) como apenas uma janela entre outras - e não a melhor delas - em sua tela. Gradativamente, páginas pessoais, blogues e redes sociais, nos quais é praxe utilizar a identidade off-line, mudam o cenário (CASTRO, ref. 3 ).

Exigências crescentes de autenticação dos usuários estão presentes nas plataformas algorítmicas. A mesma New Yorker publica em 2015 uma charge mostrando dois cachorros que olham para seu dono num computador, enquanto um deles pergunta ao outro: "Lembra-se de quando, na internet, ninguém sabia quem você era?"

Não obstante, inclusive em redes sociais como o Facebook continuam a existir identidades forjadas, por vários motivos; campanhas eleitorais, por exemplo, costumam recorrer a tais identidades, assim como a robôs. Tanto as identidades fictícias como as da "vida real" são construídas, envolvem um componente de reflexividade, e são passíveis de consolidação via performatividade.

É verdade que o anonimato e a ausência de parâmetros tão rigorosos de controle como os das plataformas atuais, garantia uma flexibilidade maior, mas toda construção está sujeita a condicionantes, pois "uma construção, afinal de contas, 
não é o mesmo que um artifício" (BUTLER, 1993, p. 94). Além disso, é possível discutir a separação entre on-line e off-line e questionar o caráter supostamente fictício de uma identidade, na medida em que ela talvez revele mais de alguém de que sua identidade em tese verdadeira; nas palavras de Lacan (1994, p. 253), "a verdade tem uma estrutura, se podemos dizer, de ficção".

De toda forma, pode-se dizer que os exercícios anônimos de construção de identidade, nas primeiras décadas da internet, preparam o terreno para o que acontece nas plataformas atuais; estamos aqui frente a variações da estratégia neoliberal mais geral de empreendedorismo de si.

As consequências mais específicas da performatividade estão associadas ao reforço de determinados perfis, e, portanto, de certas configurações de identidade, como fruto da insistência nas interpelações bem-sucedidas. Em escala coletiva, essa engrenagem leva à homofilia, o fracionamento dos ambientes virtuais em bolhas.

Ademais, diferentes tipos de performatividade produzem facetas distintas do usuário: como consumidor, perante dispositivos de comércio eletrônico; como suspeito, perante dispositivos de vigilância, e assim por diante. E, sendo o perfilamento bidirecional, isto é, contando com a contribuição do usuário, o engajamento deste pode ser subsumido ao efeito performativo de sua inserção nas plataformas.

De maneira mais lata, a performatividade nas plataformas algorítmicas leva à terceirização das escolhas. Dado que o usuário passa a confiar crescentemente nessas plataformas, a julgar que elas o conhecem melhor do que ele mesmo, sua propensão é recorrer cada vez mais a suas recomendações e repassar-lhes cada vez mais escolhas e decisões em todas as esferas da vida.

Após fornecer um input preliminar, sua agência tende a cingir-se a endossar ou não as alternativas que o algoritmo lhe expõe. Em derradeira instância, é sua própria identidade que se subordina aos algoritmos. Posto que as plataformas algorítmicas se disseminam nos diversos setores, como "estados metaestáveis e coexistentes de uma mesma modulação", para retomar a análise de Deleuze (2003, p. 243) acerca da sociedade de controle, a ascendência delas sobre o usuário generaliza-se.

Com o uso de aparelhos móveis, como celulares, o controle torna-se onipresente, acompanhando cada um em todas as atividades e em todos os lugares, e adequando-se em conformidade com as informações recebidas. Enquanto acomodação ininterrupta da plataforma aos dados captados do usuário, a modulação permite o aperfeiçoamento da interpelação e concorre para a performatividade.

Na medida em que consolida perfis, a performatividade está a serviço da governança algorítmica. Em princípio, a estabilização dos perfis facilita essa governança: se os interesses de um usuário são bem definidos, gerar recomendações a 
ele torna-se uma tarefa mais simples. Mas, não se trata tanto de um imperativo técnico, posto que os algoritmos são capazes de captar de modo relativamente rápido as mudanças nas ações do usuário que impactam seus perfis.

Se as plataformas algorítmicas induzem a performatividade, via iteração, é primordialmente para oferecer aos usuários conteúdos com os quais eles tenham maior afinidade e familiaridade, mirando atrair e reter sua atenção. Aí intervém a motivação, da parte de cada um, em buscar uma sensação de estabilidade e continuidade da identidade como um todo que projetam para si e para os outros, em que pese a multiplicidade e plasticidade de seus perfis nas plataformas.

Como, num plano mais geral, comenta Giddens (1991, p. 5), "o projeto reflexivo do eu, que consiste na sustentação de narrativas biográficas coerentes, embora continuamente revisadas, ocorre no contexto de múltipla escolha filtrada através de sistemas abstratos". Tal motivação dos usuários é potencializada pelo fato de que as plataformas, malgrado a rotatividade de seu conteúdo, conservam e amiúde exibem publicamente os registros das suas movimentações, impondo a eles a exigência de uma certa congruência do presente em relação ao passado.

Se a interpelação, como vimos, presta-se à tentativa provisória de evadir a falta inerente à condição subjetiva, a performatividade prolonga esse esforço, almejando ir além de tal provisoriedade. Isso implica, por um lado, que a identidade não é dada de antemão, é algo flexível, fruto de uma construção; por outro, que a repetição pode conferir certa estabilidade a elementos da identidade. Esses aspectos aparentemente contraditórios da performatividade - flexibilidade e estabilidade - apresentam-se articulados nas plataformas algorítmicas, mas essa articulação não é isenta de tensões.

A ideia de performatividade concatena-se com a de performance como representação para outrem, envolvendo uma teatralidade, como assinala Butler (2006, p. 190, grifos da autora): "Consideremos o gênero, por exemplo, como um estilo corporal, um 'ato', por assim dizer, que tanto é intencional como performativo, onde 'performativo' sugere uma construção dramática e contingente do sentido". Isso está presente nas plataformas algorítmicas, que colocam cada usuário em contato permanente com muitos outros.

Elas favorecem o surgimento de expedientes de comparação e confronto entre os usuários e a aproximação entre aqueles com interesses afins, reunidos em nichos com perfil comum. Relatos de experiências, manifestações de preferências, externalizações de opiniões, exibições da rede de contatos, tudo isso conflui para a composição de uma identidade com a consciência de estar permanentemente sob o escrutínio do Outro. Responder à interpelação significa dar conta ao mesmo tempo de uma demanda por parte do algoritmo e de uma 
demanda por parte de outros usuários veiculada pelo algoritmo, esta última implicando a performance enquanto representação.

Performatividade remete também a performance na acepção de desempenho, nota Lyotard:

\footnotetext{
Em teoria da linguagem, performativo assumiu desde Austin um sentido preciso [...]. Vamos reencontrá-lo mais adiante associado aos termos performance e performatividade (de um sistema, notadamente) no sentido que se tornou corrente de eficiência mensurável na relação entrada/saída. Os dois sentidos não são estranhos um ao outro. O performativo de Austin realiza a performance ótima (LYOTARD, 1979, p. 21, grifos do autor).
}

As plataformas algorítmicas são impelidas por resultados: quanto maior o nível de atividade, mais dados elas acumulam e maior seu potencial de lucratividade. Isso se projeta nos usuários, incitados a dinamizar suas ações e servir, consequentemente, aos desígnios da plataforma.

Tal preocupação é estimulada pelo cotejo com outros e pela quantificação generalizada. Todos se avaliam mutuamente: motorista e passageiro no Uber, anfitrião e hóspede no Airbnb, amigos no Facebook etc. Assim, quando um usuário atende à interpelação da plataforma, está igualmente no encalço de desempenho.

A performance, como desempenho, fomenta a performatividade, como produção de identidade através da conduta. A primeira responde a uma pressão exercida em si mesmo pelo usuário com o auxílio da interiorização de injunções externas, ao passo que a segunda equivale à adesão aos modelos oferecidos pela interpelação.

\section{Considerações finais}

A articulação das categorias conceituais de interpelação, perfilamento e performatividade para entender como o usuário é governado no interior das plataformas algorítmicas permite iluminar a peculiar relação entre controle e agência que se estabelece nessas plataformas e caracteriza a governança via algoritmos.

Com efeito, o que se verifica aqui não é uma simples oposição entre controle e agência, na qual cada polo se fortalece necessariamente às expensas do outro, mas uma interpenetração, na qual a latitude da agência do usuário concorre para a maior eficácia de seu controle pela plataforma, e simetricamente a eficácia do controle pressupõe a latitude da agência. 
Essa interpenetração entre controle e agência se apoia na recursividade da interpelação - cada usuário é abordado a partir de dados que ele próprio disponibiliza de uma forma ou de outra; na flexibilidade do perfilamento - essa abordagem pode incidir sobre uma variedade de perfis distintos; e na contingência da performatividade - os perfis que ganham proeminência são aqueles mais recorrentes na interação entre o usuário e o algoritmo.

\section{REFERÊNCIAS}

ALTHUSSER, Louis. Sur la reproduction. Paris: Presses Universitaires de France, 1995.

APPADURAI, Arjun. Banking on words: the failure of language in the age of derivative finance. Chicago and London: University of Chicago Press, 2016. https://doi.org/10.1111/amet.12397

AUSTIN, J. L. How to do things with words: the William James Lectures delivered at Harvard University in 1955. Oxford: Clarendon Press, 1962. https://doi.org/10.1111/j.1468-0149.1963.tboo768.x

BEAUVOIR, Simone de. Le deuxième sexe, tome II. Paris: Gallimard, 1949.

BERNERS-LEE, Tim. Long live the Web. Scientific American, New York, v. 303, n. 6, p. 80-85, dez. 2010. https://doi.org/10.1038/scientificamerican1210-80

BUTLER, Judith. Bodies that matter: on the discursive limits of "sex". New York and London: Routledge, 1993.

BUTLER, Judith. The psychic life of power: theories in subjection. Stanford: Stanford University Press, 1997.

BUTLER, Judith. Gender trouble: feminism and the subversion of identity. New York and London: Routledge, 2006.

DEAN, Jodi. Crowds and party. London and New York: Verso, 2016.

DELEUZE, Gilles. Pourparlers: 1972-1990. Paris: Minuit, 2003.

DERRIDA, Jacques. De la grammatologie. Paris: Minuit, 1967.

DERRIDA, Jacques. Limited Inc. Translated by Samuel Weber and Jeffrey Mehlman. Evanston: Northwestern University Press, 1988.

DOLAR, Mladen. A voice and nothing more. Cambridge (MA) and London: MIT Press, 2006. FERGUSON, Charles H. What's next for Google. MIT Technology Review, Cambridge (MA), Jan. 2005. 
FLUSSER, Vilém. O universo das imagens técnicas: elogio da superficialidade. São Paulo: Annablume, 2008. https://doi.org/10.14195/978-989-26-1129-7

FOUCAULT, Michel. À propos de la généalogie de l'éthique: un aperçu du travail en cours. In: Dits et écrits, 1954-1988, tome IV: 1980-1988. Paris: Gallimard, 1994a. p. 383411. https://doi.org/10.14375/np.9782070739899

FOUCAULT, Michel. L'écriture de soi. In: Dits et écrits, 1954-1988, tome IV: 1980-1988. Paris: Gallimard, 1994b. p. 415-430. https://doi.org/10.14375/np.9782070739899

FOUCAULT, Michel. L’herméneutique du sujet: cours au Collège de France, 1981-1982. Paris: Gallimard/Seuil, 2001. https://doi.org/10.22439/fs.voi8.2918

FOUCAULT, Michel, Michel. Naissance de la biopolitique: cours au Collège de France, 1978-1979. Paris: Gallimard/Seuil, 2004. https://doi.org/10.22439/fs.voi8.2918

FREUD, Sigmund. Gesammelte Werke, vierter Band: Zur Psychopathologie des Alltagslebens. London: Imago, 1941.

FREUD, Sigmund. Die Traumdeutung. In: Gesammelte Werke, zweiter und dritter Band: Die Traumdeutung, Über den Traum. 3. Aufl. Frankfurt am Main: S. Fischer, 1961. https://doi.org/10.1007/978-3-476-04483-9 21

FREUD, Sigmund. Massenpsychologie und Ich-Analyse. In: Gesammelte Werke, dreizehnter Band: Jenseits des Lustprinzips / Massenpsychologie und Ich-Analyse / Das Ich und das Es. 5. Aufl. Frankfurt am Main: S. Fischer, 1967a. p. 71-161.

FREUD, Sigmund. Das Ich und das Es. In: Gesammelte Werke, dreizehnter Band: Jenseits des Lustprinzips / Massenpsychologie und Ich-Analyse / Das Ich und das Es. 5. Aufl. Frankfurt am Main: S. Fischer, 1967b. p. 235-289. https://doi.org/10.1007/978-3-642-94469-7 3

FRIEDMAN, Thomas L. Is Google God? The New York Times, New York, Jun. 29, 2003.

GALLOWAY, Alexander R. Protocol: how control exists after decentralization. Cambridge (MA) and London: MIT Press, 2004.

GIDDENS, Anthony. Modernity and self-identity: self and society in the late modern age. Cambridge (UK): Polity, 1991.

GLEICK, James. How Google dominates us. The New York Review of Books, New York, Aug. 18, 2011.

HAYLES, N. Katherine. My mother was a computer: digital subjects and literary texts. Chicago and London: University of Chicago Press, 2005. https://doi.org/10.1177/026 32764080250050802 
HOCHMAIR, Hartwig H.; LUTTICH, Klaus. An analysis of the navigation metaphor - and why it works for the World Wide Web. Spatial Cognition and Computation, Hingham, v. 6, n. 3, p. 235-278, 2006. https://doi.org/10.1207/s15427633scc0603 3

KITTLER, Friedrich. Grammophon film typewriter. Berlin: Brinkmann \& Bose, 1986.

KITTLER, Friedrich A. The truth of the technological world: essays on the genealogy of presence. Translated by Erik Butler. Stanford: Stanford University Press, 2014.

KOWALSKI, Robert. Algorithm = logic + control. Communications of the ACM, New York, v. 22, n. 7, p. 424-436, Jul. 1979.

LACAN, Jacques. Écrits. Paris: Seuil, 1966.

LACAN, Jacques. Le séminaire, livre I : les écrits techniques de Freud. Paris: Seuil, 1975.

LACAN, Jacques. Le séminaire, livre II: le moi dans la théorie de Freud et dans la technique de la psychanalyse. Paris: Seuil, 1978. https://doi.org/10.3917/fp.017.0181

LACAN, Jacques. Le séminaire, livre IV : la relation d'objet. Paris: Seuil, 1994.

LESSIG, Lawrence. Code: version 2.0. New York: Basic Books, 2006.

LYOTARD, Jean-François. La condition postmoderne: rapport sur le savoir. Paris: Minuit, 1979.

MACPHERSON, Matt. The Church of Google. Feb 1, 2008. Disponível em: https://web. archive.org/web/20080201145525/http://www.churchofgoogle.org:80/ Acesso em: 26 mar. 2019.

MANOVICH, Lev. The language of new media. Cambridge (MA) and London: MIT Press, 2001.

MARX, Karl. Das Kapital: Kritik der Politischen Ökonomie, Book I - der Produktionsprozess des Kapitals. In: MARX, Karl; ENGELS, Friedrich. Werke, Band 23. Berlin: Dietz, 1962. https://doi.org/10.1515/9783050076553-003

MORRISON, Aimée. Facebook and coaxed affordances. In: POLETTI, Anna; RAK, Julie (Eds.). Identity technologies: constructing the self online. Madison and London: University of Wisconsin Press, 2014. p. 112-131.

NIELSEN, Jakob. The art of navigating through hypertext. Communications of the ACM, New York, v. 33, n. 3, p. 296-310, mar. 1990. https://doi.org/10.1145/77481.77483

OTTERLO, Martijn van. Automated experimentation in Walden 3.0: the next step in profiling, predicting, control and surveillance. Surveillance \& Society, Sheffield, v. 12, n. 2, p. 255-272, 2014. https://doi.org/10.24908/ss.v12i2.4600 
PASQUALE, Frank. The black box society: the secret algorithms that control money and information. Cambridge (MA) and London: Harvard University Press, 2015. https:// doi.org/10.4159/harvard.9780674736061

POSTER, Mark. The second media age. Cambridge (UK): Polity Press/Cambridge (MA): Basil Blackwell, 1995.

SILVEIRA, Paulo. Ideologia, indivíduo, sujeito. Cadernos de subjetividade, São Paulo, n. esp. Louis Althusser, p. 25-37, 1994.

SIMONDON, Gilbert. L'amplification dans les processus d'information. In: Communication et information: cours et conférences. Chatou: La Transparence, 2010. p. 157-176.

TURKLE, Sherry. Life on the screen: identity in the age of the Internet. New York: Touchstone, 1997.

WIENER, Norbert. Cybernetics, or Control and communication in the animal and the machine. 2nd ed. Cambridge: MIT Press, 1961.

ŽIŽEK, Slavoj. Tarrying with the negative: Kant, Hegel, and the critique of ideology. Durham: Duke University Press, 1993. https://doi.org/10.1215/9780822381822

\section{Dados do autor:}

Julio Cesar Lemes de Castro - e-mail: julio@jclcastro.com.br.

Pesquisador de pós-doutorado em Comunicação e Cultura na Uniso, com bolsa PNPD/Capes. Graduado em Jornalismo pela Escola de Comunicações e Artes da USP, com mestrado e doutorado em Comunicação e Semiótica na PUC-SP, pós-doutorado em Psicologia Social na USP e pós-doutorado em Comunicação e Cultura na UFRJ.

\section{Endereço do autor:}

$1^{\circ}$ Piso da Biblioteca "Aluísio de Almeida" - Universidade de Sorocaba (Uniso)Cidade Universitária Professor Aldo Vannucchi, Rod. Raposo Tavares, Km 92.5Sorocaba, São Paulo, Brasil 18023-000 